Please cite the published version, which appeared in New Waves in Aesthetics, ed. Kathleen Stock and Katherine Thomson-Jones (Palgrave Macmillan, 2008), 1-19.

\title{
The Ontological Diversity of Visual Artworks Sherri Irvin
}

Virtually everyone who has advanced an ontology of art has accepted a constraint to the effect that claims about ontology should cohere with the sort of appreciative claims made about artworks within a mature and reflective version of critical practice. In this paper, I argue that such a constraint, which I agree is appropriate, rules out a one-size-fits-all ontology of contemporary visual art (and thus of visual art in general). Mature critical practice with respect to contemporary art accords artists a significant degree of stipulative authority regarding the features and boundaries of their works. As I will show, this results in ontological variation among visual artworks. Any claim to the effect that all works belong to the same ontological category will thus come out false or uninformative. Interesting, substantive claims about ontological status can be made only in relation to specific works; that is, we must consider the ontological status of each contemporary artwork individually. The only general ontological claim that can be made about visual artworks (and also about artworks in other forms) is that they belong to the sort of thing that artists create. But this is not a substantive ontological claim.

\section{The critical practice constraint}

There was a time, a hundred years ago or so, when visual artworks seemed to be pretty straightforward things, and the ontology of art might have seemed a correspondingly simple problem, especially to those preoccupied with painting. Artists made paintings by putting paint on a support, often a canvas. Like other products, paintings could be bought and sold: the seller would deliver the painted canvas into the hands of the buyer, who now had a property right in it. Paintings could also be destroyed, and the destruction of a painting was something like the destruction of your favourite party dress: the physical object didn't necessarily cease to exist, but it lost at least some of the features that made it worth looking at. Similar stories can be told about drawings, carved sculptures and so forth. ${ }^{1}$ Moreover, artists spend a great deal of time crafting objects, enthusiasts spend a great deal of time viewing them, and museums spend vast resources exhibiting, storing, and conserving them. We refer to the works in question as visual artworks, suggesting that the primary appreciative act is one of looking; and what, if not a physical entity, can be looked at?

For these reasons, the temptation has been strong to think that visual artworks simply are physical objects. What could give us grounds for rejecting this straightforward idea? The resistance to the identification of artworks and physical objects has typically been grounded, implicitly or explicitly, in some sort of critical practice constraint. A critical practice constraint is a methodological principle to the effect that

[a]rtworks must be entities that can bear the sorts of properties rightly ascribed to what are termed 'works' in our reflective critical and appreciative practice; that are individuated in the way such 'works' are or would be individuated[;] and that have the modal properties that are reasonably ascribed to 'works', in that practice. ${ }^{2}$

\footnotetext{
${ }^{1}$ Artworks with multiple instances, like prints and cast sculptures, have always complicated this picture. In such cases, the artwork cannot be identical to any particular physical object, since it can survive the destruction of any particular instance (except, in some cases, the last instance).

2 David Davies, Art as Performance (Malden, MA: Blackwell, 2004), p. 18. In Art as Performance, Davies refers to this constraint as the 'pragmatic constraint'. He employs the term 'critical practice constraint', which I favour, in 'Artwork, Action, and Process', Acta Analytica 20 (1988), 131-153. As Davies notes, Jerrold Levinson explicitly employs a similar constraint in 'What a Musical Work Is', Journal of Philosophy 77 (1980), 5-28.
} 
Whatever we take the artwork to be, then, it must be the sort of entity which possesses the properties we attribute to artworks, or otherwise makes sense of the claims we make, in appropriate practices of interpretation and appreciation. The critical practice constraint is an acknowledgement of the fact that artworks, unlike such things as stars and water molecules, have no existence independent of human interests and practices. As David Davies puts it, 'the very notions of "art" and "artwork" are parasitic upon [critical] practiceartworks just are the things that play a particular kind of role in a particular kind of

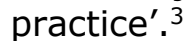

Davies and Gregory Currie argue at length that a central tenet of critical practice is that the artwork is something achieved by the artist. Judgments about the quality of an artwork, Currie argues, rely centrally on knowledge about what the artist achieved in creating it. ${ }^{4}$ Davies develops at length the idea that grasping the artwork involves recognizing an artistic statement that has been finely articulated in a medium. ${ }^{5}$ Davies and Currie agree that these insights about appreciation of artworks require us to attend carefully to the artist's creative activity. Indeed, they hold that the artwork should be identified with that creative activity rather than with any object or structure the activity gives rise to. On Currie's view, the true artwork is the action-type of discovering a certain structure through a certain process (which he refers to as a 'heuristic path'). ${ }^{6}$

Davies, too, holds that the artwork is to be identified not with a structure produced or presented by the artist, but with the artist's generative act. Davies argues that our intuitions and statements about an artwork cannot coherently be made true of one and the same entity. Some statements, particularly about what is achieved through the work, refer to the artist's creative activity, while other statements, such as those about formal features, refer to the 'focus of appreciation' (that is, the physical object, performance, conceptual structure, etc., presented by the artist for our attention). ${ }^{7}$ Davies holds that it is only by attending carefully to the artist's generative activity that we can appreciate the statement the artist has articulated. For this reason, in appreciating the artwork we are in effect appreciating that activity; and this shows that the artwork should be seen as equivalent to the activity, not to the focus of appreciation. ${ }^{8}$

It is quickly obvious that Currie's and Davies' views fail to preserve the truth of many intuitive statements about artworks. For instance, it will be false to say of Picasso's artwork Les Demoiselles d'Avignon that it hangs in the Museum of Modern Art, that it has a patch of brown in the upper left corner, or that it depicts women in a brothel, since these are not properties of the action Picasso undertook in creating the painted canvas. However, Currie and Davies hold that their views provide the best way of making another important set of

Richard Wollheim's Art and Its Objects, $2^{\text {nd }}$ edition (Cambridge: Cambridge University Press, 1980) and Arthur Danto's The Transfiguration of the Commonplace: A Philosophy of Art (Cambridge, MA: Harvard University Press, 1981) are also deeply informed by an implicit critical practice constraint.

3 Davies, Art as Performance, p. 21.

${ }^{4}$ Gregory Currie, An Ontology of Art (New York: St. Martin's Press, 1989), esp. pp. 36-40.

${ }^{5}$ Davies, Art as Performance, pp. $52 \mathrm{ff}$.

${ }^{6}$ Currie, Ontology, esp. pp. 66-71. By 'structure', Currie refers to such things as 'a certain pattern of lines and colours, structure of sounds, or sequence of words' (p. 47).

7 Davies describes a focus of appreciation as the 'outcome or product of a generative performance on the part of one or more individuals' (Art as Performance, p. 26, emphasis in original). Though there are differences between Currie's notion of a structure and Davies's notion of a focus of appreciation, nothing hangs on this point for the sake of the present argument. I will use the term 'focus of appreciation' to describe the product of the artist's activity in relation to both Currie's and Davies' views.

8 Davies' view diverges from Currie's in that Davies holds, on the basis of reasons I will not rehearse here, that it is preferable to see the artwork as a particular token of creative activity rather than an action-type. 
critical and appreciative statements come out true: namely, such statements as 'Les Demoiselles d'Avignon was revolutionary.' Picasso's action, which was committed in a certain context with certain considerations in mind and in response to particular arthistorical developments, clearly has the characteristic of being revolutionary. But the characteristic of being revolutionary cannot be appropriately attributed to a piece of canvas with pigment on it, since an object with exactly the same physical properties could have been produced through a completely different generative act, perhaps with nothing revolutionary about it. ${ }^{9}$

An advantage of Currie's and Davies' views is ontological unity: on Currie's view, every artwork belonging to whatever form or genre is an action-type, while on Davies' view every artwork is an action-token. Thus even the distinction between singular arts (like painting and carved sculpture) and multiple arts (like most cast sculpture and music for performance) turns out to be insignificant as it concerns the ontology of artworks, for in every case the work is simply the artist's (type or token) generative act, and a generative act belongs to the same ontological category regardless of what is thereby created or discovered. Moreover, as Currie points out, his view is ontologically conservative, assigning all artworks to a familiar category: actions belong to the category of events, a respectable category that seems necessary to any viable account of the world.

I agree with Currie's and Davies' claim that critical practice makes evident a very intimate connection between the artwork and the activity of the artist. This is true also of standard institutional practice: upon acquisition of contemporary artworks, curators and conservators collect extensive information from artists to guide their practices of storage, conservation, and display. Even after a work has been in a collection for many years, the artist, if still living, may be consulted about restoration or invited to the institution to participate in installation. ${ }^{10}$ These practices reveal that the artist is taken to have special authority about the nature and disposition of the work. In what follows, I will appeal to widespread institutional practices of individuation, treatment and display of artworks as well as to practices of appreciation and interpretation, which tend to depend upon and be responsive to the former.

While agreeing that the artist's activity is centrally important to the artwork, I disagree with the conclusion that we must therefore see the work as identical to that activity. It is in fact possible to account for all of the properties we commonly and appropriately attribute to artworks without referring them to two different entities. To account for achievement-related aspects of the work, even while identifying the work with the focus of appreciation, we can appeal to relational properties: every focus of appreciation has the property of having been created through a certain process. Thus everything required to account for achievement-related properties does belong to the focus of appreciation proper. ${ }^{11}$ Of course, if we identify the focus of appreciation with a particular physical object (in cases where such an object is available), then the problem of modal properties will arise: if, as seems plausible, the focus of appreciation has its process-related properties essentially, but the physical object does not, the identity and persistence conditions of the two kinds of entity will differ. ${ }^{12}$ But rather than driving us to the view that

${ }^{9}$ For such an argument, see especially Currie, Ontology, pp. 50-53.

${ }^{10}$ For description of actual cases, see Sherri Irvin, 'The Artist's Sanction in Contemporary Art', Journal of Aesthetics and Art Criticism 63 (2005), 315-326; and 'Museums and the Shaping of Contemporary Artworks', Museum Management and Curatorship 21 (2006), 143156.

${ }^{11}$ Kathleen Stock makes a similar point in her review of Art as Performance, Philosophical Quarterly 55 (2005), 695.

12 Robert Stecker argues that this concern can be dealt with by allowing that two distinct physical objects of different kinds can occupy the same spatiotemporal position. As we will see, though, some artworks cannot plausibly be construed as identical to or constituted by physical objects even on this more liberal notion. See Stecker, 'The Ontology of Art 
the 'true' artwork is an action, this observation should lead us to develop an account of the focus of appreciation that does not identify it with a physical object construed independently of its relational properties. It is to this task that I now turn.

\section{Artworks as things the artist creates}

An appropriate understanding of the critical practice constraint should lead us, then, to turn our attention to the focus of appreciation. I will present an account of the artwork, construed as a focus of appreciation, that incorporates all the properties that are appropriately attributed to artworks in practices of interpretation and appreciation. As this account has been argued for in detail elsewhere, ${ }^{13}$ I will focus here on showing how the account applies to a particular contemporary artwork and some hypothetical variations on it, and showing how it allows us to account for the idea that the work is something achieved by the artist while satisfying the widespread intuition that an artwork is an entity created and presented by the artist for our perusal, not the artist's activity of creation and presentation.

In my view, artworks acquire their features through a diverse array of art-making activities. In addition to making or selecting some physical object, structure, event, process, or state of affairs, the artist often specifies details of presentation, which may include acceptable venues and physical configurations. Even works in the traditional genre of painting are partly constituted by the specification of an acceptable configuration: every traditional painting has an orientation that counts as right side up (as was highlighted by Georg Baselitz when he stipulated that his paintings were to be hung so that their representational content was upside down). The artist may also specify certain properties related to the meaning of the work, such as the title; and this will constrain how it is appropriate to interpret the work. ${ }^{14}$ I describe this determination of the work's properties through the artist's acts of art-making as the artist's sanctioning of certain features of the work.

Not all sanctioning of artwork features is done explicitly. Established artistic genres involve conventions that determine some of the work's features. For example, a traditional painter did not have to declare that all future paint flaking is irrelevant to the nature of the artwork. Instead, traditional paintings fall under a strong convention to the effect that, when arms break off sculptures and paint flakes off paintings, we do not come to see them as armless-artworks and flaking-artworks, or interpret their subjects as armless humans or landscapes punctuated by strange, irregularly shaped patches of emptiness. Ordinarily, unless the artist explicitly stipulates otherwise, damage to the objects the artist created is not interpretatively relevant. It is not, then, necessary for the artist to explicitly sanction every one of a work's features either by giving the object certain characteristics or by saying something about whether the work has this or that feature; if it were, then no work would ever be completed, because an infinite number of possible features would have to be ruled out. The artist's sanction determines the artwork's features in the context of conventions that specify default artwork boundaries.

Many such conventions are defeasible. It is perfectly open to a contemporary artist to stipulate that the flaking of a painting is a bona fide feature of the work. The Japanese Gutai artist Saburo Murakami did just that. In 1957, he created a series of Peeling Off paintings which are such that the flaking paint is interpretatively and evaluatively

Interpretation', in Stephen Davies and Ananta C. Sukla (eds.), Art and Essence (Westport, CT: Praeger, 2003), pp. 177-191, section IV.

${ }^{13}$ Irvin, 'The Artist's Sanction'.

${ }^{14}$ However, simply giving the work a title is not sufficient to imbue the work with particular representational content. Whether or not the artist has made a picture of, say, a banyan tree will depend partly on our conventions and practices for decoding pictorial representations, partly on what banyan trees actually look like, and so forth. 
relevant: ${ }^{15}$ when we consider what the work accomplishes, we should consider such things as the statement that is made by embracing the flaking of the paint, and the beauty or ugliness of the surface that emerges as the paint flakes.

It should be mentioned that not every statement made by the artist serves to sanction features of the artwork. I distinguish between the features of the work and its interpretation, where the latter is constrained but not wholly determined by the former. The artist has the authority to sanction the work's features, but not (directly) to fix the appropriate interpretation of the work. When artists make statements about messages purportedly conveyed by their works, for instance, these statements ordinarily have no more force than those of ordinary interpreters. ${ }^{16}$

It is also possible for an artist to try but fail to establish a sanction about something that does fall within the domain where sanctioning is possible. If the artist's preference about configuration of the work is not expressed clearly, or is mistakenly expressed to a museum visitor who happens to resemble the curator, then no sanction has been established. And if the artist makes contradictory statements, or expresses preferences that it would be dangerous or impossible to carry out within the framework of the institution, it may be necessary to rely on art world or institutional conventions to resolve the issue of what we should take to have been sanctioned. ${ }^{17}$

In typical cases, many of the work's features are sanctioned simply through the artist's act of making a particular physical object. Kandinsky's application of paint to canvas was the act through which he sanctioned most of the features of his works. He also sanctioned a configuration of the artwork, namely that a particular orientation counts as right-side-up. But, as we will see, in some instances the creation of the work doesn't involve the artist's making or even selecting a particular object. In such instances there is no plausible identity or constitution relation that could hold between the artwork and a particular physical object.

The artwork, then, is the entity that realizes the parameters sanctioned by the artist. The artist's acts of creation and presentation are acts of articulating this entity, and they shape the properties of the entity in ways that are relevant to appreciation and interpretation. The ontological status of the entity will differ from case to case: in some instances it may be a particular physical object, or a particular token event, while in others it is any assemblage of objects that satisfies the conditions specified by the artist. In some instances, indeed, the artwork may be a generative activity that eventuates in some physical object or structure; some works of performance art, such as those of Yves Klein's happenings during which paintings were created, are best described in this way.

It might be thought a cost of my account that visual artworks do not end up belonging to a single ontological category. However, insofar as focuses of appreciation appear to belong to diverse ontological categories even on the views of Currie and Davies, ${ }^{18}$ it is not clear that my account ultimately requires more categories than theirs. Moreover, it is a virtue of my view that it allows us to distinguish between certain works of performance art, where what is presented for our attention really is the artist's creative activity, and traditional visual artworks where the entity presented for our attention is a physical object appropriately displayed.

\section{The ontological diversity of artworks}

\footnotetext{
15 Paul Schimmel, 'Intentionality and Performance-Based Art', in Miguel Angel Corzo (ed.), Mortality Immortality? The Legacy of 20th-Century Art (Los Angeles: Getty Conservation Institute, 1999), p. 137.

${ }^{16}$ For further discussion, see Irvin, 'The Artist's Sanction'.

17 Space constraints prevent me from discussing this important issue in detail. Some such cases are treated in Irvin, 'Museums'.

${ }^{18}$ I see no denial of this claim in Davies' or Currie's works. Moreover, insofar as ontological unity is to count as an advantage of their views, it must be the case that focuses of appreciation are ontologically diverse.
} 
If we take artworks to acquire their features through a process of sanctioning by the artist, as I suggest, we must conclude that artworks are ontologically diverse. This is because artists, implicitly or explicitly, sanction different kinds of entity in different cases. To illustrate, I will consider a particular contemporary artwork and a number of hypothetical variations on it. Felix Gonzalez-Torres's 1991 Untitled (Portrait of Ross in L.A.) involves a pile of hard candies in colourful wrappers. The particular hard candies displayed on a given occasion are not essential, however: viewers are invited to consume them as desired, and gallery staff periodically replenish them, in accordance with Gonzalez-Torres's instructions. The size of the pile is ideally determined by weight: it should add up to 175 pounds of candy. But even this isn't definitive. Whenever someone takes candy out of the pile, the weight will be less than ideal. And, presumably, gallery staff don't weigh all the candy when they add to the pile; they just attempt a visual approximation of the initial installation.

Untitled relates to the death from AIDS of Gonzalez-Torres's lover, Ross Laycock, and the ideal weight of the pile is related to Ross's ideal body weight. ${ }^{19}$ So the work, while appearing fun-loving and light-hearted, in fact explores issues of mortality and of the squeamishness and fear surrounding AIDS: since this is a portrait of Ross, we are symbolically consuming him, although many would have been reluctant even to touch him during his illness. Untitled and other consumable candy works by Gonzalez-Torres are also compelling in an art context, even for those who know nothing about Ross and his death from AIDS: it can be wonderful, after spending a day in a museum looking hard at beautiful and perplexing and remote things, to be able to pick up a piece of an artwork and lay claim to it, or, better yet, to be able to eat it and appreciate its sweetness. There is something generous about these works (and something interesting about the way they enlist the museum in this generosity). The candy works also raise questions about the nature of the experience we expect and receive from art. We tend to treat artworks as great cultural treasures, but is the enrichment we receive from them, especially after museum fatigue has set in, really greater than the fleeting but real and immediate enjoyment of a piece of candy? To what extent should artists play to the viewer's desire for a reward?

It should be immediately clear that this work is not like a traditional sculpture. ${ }^{20}$ Every particular physical component is replaceable; indeed, the work can survive $100 \%$ replacement of the candies. For traditional sculptures, on the other hand, every physical component is essential, and if a piece is lost it cannot simply be replaced by a look-alike. ${ }^{21}$

Gonzalez-Torres's work, then, is not identical to the particular candies that are dumped on the floor the first day of the exhibition. One might think, however, that the work is identical to a particular pile of candy, where a pile of candy is a physical entity that can survive the gradual replacement of all the particular candies it contained when it was first constituted. This possibility is interpretatively attractive, in that a pile of candy is similar to a human body in this respect: human bodies are physical objects that survive the gradual replacement of their physical components. In this way, then, the construal of the work as a pile of candy would connect it to the body of Ross. ${ }^{22}$

${ }^{19}$ Sautman, Anne, Self-Guide: Modern and Contemporary Art at the Art Institute (Chicago: Art Institute of Chicago, 2003), p. 8.

20 Neither, though, is it purely conceptual. Comparison of Untitled (Portrait of Ross in L.A.) with other Gonzalez-Torres works, such as the 1991 Untitled (Placebo), involving 1000 to 1200 pounds of candies wrapped in silver and displayed in a neat rectangular array on the floor, shows that Gonzalez-Torres gives sculptural attention to the visual details of his work, and visual appearance is part of what viewers should and do consider in appreciation and interpretation.

${ }^{21}$ See Mark Sagoff, 'On Restoring and Reproducing Art', The Journal of Philosophy 75 (1978), 453-470, for discussion of this point in relation to the Vatican restoration of Michelangelo's Pietà. Of course, replacement parts can supply considerable information about what the original was like; but to encounter even an excellent replica is not to encounter the original work.

${ }^{22}$ I am grateful to Jason Southworth for this point. 
If the work were a pile of candies, however, the work would cease to exist whenever the pile ceases to exist. Were the curators negligent in restocking the candies on a busy weekend, the work might accidentally be destroyed. And were the museum to discard the remaining candies between exhibitions, they would have destroyed the work. But in fact, there is nothing in critical or institutional practice to support the idea that the work can be destroyed in this way, or that it is an entity with discontinuous existence. Works of this type, which involve the assembly of new materials for each display, continue to belong to museum collections, and are spoken of by critics in the present tense, even when years elapse between exhibitions. ${ }^{23}$ Moreover, regarding the work as existing discontinuously would make it out to be a very odd sort of thing indeed: a non-contiguous entity in 4dimensional spacetime, made up of a series of piles.

Gonzalez-Torres's work thus has a complex relationship to any particular pile of candies through which it is presented: it clearly is not identical to the pile, and it is constituted by some pile or other at most partially and intermittently, like a soul moving from body to body. Before considering the actual work's ontological status further, let us consider some alternatives, superficially similar to Untitled.

1) In selling the work to the museum, the artist delivers a particular 175-pound batch of candy, with instructions that, for display, the candy is to be placed in a pile in the corner of the room. No mention is made that the candy may be eaten.

2) The work resembles the actual case in all respects, except that the artist's instructions specify that when all the candies have been eaten, they are not to be replenished.

3) The instructions are the same as in the actual case (the candies may be eaten and are to be periodically replenished), but the museum curator decides that visitors should not be allowed to eat the candies. Thus the presentation ends up being the same as that specified in 1.

4) The work is like that in case 2, except that the artist stipulates that the work may legitimately be presented anywhere, at any time, if his instructions are followed. ${ }^{24}$ When all the candies have been eaten, then, a new instance of the work may be constructed, just as a musical work may be performed again after a particular performance has ended. ${ }^{25}$

How should we understand the work in cases 1-4? It seems clear that in case 1, we should see the work as a case of sculpture. The artist is presenting the pile of candies as an artefact to be put on display, stored between exhibitions, and so forth. In the absence of any indication to the contrary, the candies will be treated by the institution as essential to the work, and will thus be subjected to careful storage and conservation procedures.

It is clear that this work functions, interpretatively, quite differently from the actual work: it does not offer the same sense of generosity; it does not challenge the taboos associated with AIDS in the same way; and, rather than poking fun at the distance that institutions often impose between artworks and viewers by subverting it and allowing the candy to be consumed, it pokes fun at this distance by preserving it and directing it at an object with respect to which such distance seems completely ridiculous. The work still

${ }^{23}$ Another prominent example is Jana Sterbak's Vanitas: Flesh Dress for an Albino Anorectic, exhibition of which requires that a dress be sewn from large pieces of flank steak. ${ }^{24}$ Sol LeWitt's wall drawings function in this way: he allows that anyone who follows his instructions precisely will have constructed a genuine LeWitt, whether or not LeWitt is aware of or authorizes the activity.

${ }^{25}$ One might wonder whether the actual work should be regarded as an abstract entity, such that each pile of candies is a token or instance of the work. While I think that criticism and institutional convention regarding this and similar works supports the idea that they are singular entities rather than multiply instantiable abstractions, I will leave this matter aside for the present. The 4 cases are sufficient to establish the ontological diversity of artworks, regardless of the verdict about the actual work. 
comments on many of the same issues, but coldly and sarcastically rather than in a playful and inviting way: since Ross has AIDS, we cannot physically engage even with his symbolic stand-in; since artworks are precious objects with which we are not permitted to engage, we cannot eat even a simple, easily replaceable piece of candy on the floor of a gallery, as long as it is part of an artwork. This version of the work takes the institutional imposition of distance as an unfortunate given, a lamentable convention that we're stuck with, whereas Gonzalez-Torres's actual work, rather than adopting such a defeatist mode, proposes that this distance is something art can light-heartedly shed. The nature of the commentary that this work makes on matters of institutional distance depends upon its essential constitution relation to a particular physical object that will be protected and conserved by the museum.

The work described in case 2 is different, in important ways, both from the actual work and from the work described in case 1 . Because eating of the candies is permitted in case 2, this work doesn't maintain the sense of institutional distance present in case 1. But, whereas the actual work is characterized by inexhaustibility and generosity, and gives us a tribute in which the artist's love for Ross is immortalized, the work in case 2 confronts us very firmly with the finiteness of things. Each time we take a piece of candy, we must recognize that we are hastening the work's demise, just as Ross's demise was hastened by his disease. Should we eat a piece and thus enjoy the full experience of the work, or should we be frugal, simply imagining what it would be like to eat one of the candies, so that the work can last longer? Who will eat the last candy, and thus consign the work forever to oblivion? Seeing the work as essentially constituted by a particular physical object allows us to understand it as making a particularly poignant commentary on mortality. However, as we see by comparing case 2 with case 1 , ontological status is only one factor among others; works belonging to the same or similar ontological categories can have quite different interpretative contents.

Now consider case 3, in which the instructions are exactly as in the actual case: the pile is ideally 175 pounds, but it is permissible for audience members to eat the candies; the pile is to be replenished indefinitely. However, a curator decides, for some reason, that audience members are not to be allowed to eat the candies; or perhaps museum guards are ignorant of the instruction that the candies may be eaten, and thus they prevent audience members from approaching them.

Notice that what the audience will experience, in case 3, is just what they would have experienced in case 1. And the evolution (or lack thereof) of the pile of candies will also be the same as in case 1 . But should we therefore interpret the work as being different than it is in the actual case? No: the fact that a curator makes a decision to present things incorrectly doesn't change what the work itself is or how it should be understood. ${ }^{26}$ It might make it harder for audience members to grasp the work, just as hanging a painting upsidedown might make it more difficult for the audience to grasp the work. But it does not change what it is appropriate to say in interpretation or evaluation of the work. Only the artist can make decisions that will change the work's properties (unless the artist explicitly yields that power to others). For this reason, the work in case 3 is the same as in the actual case, despite the fact that the presentation differs. And the ontological status of the work in case 3 differs from that of the work in case 1, though the presentation is equivalent.

Let us now turn to case 4 . In this case, the artist's sanction determines that the work is an abstract entity, since it may have more than one instance. The work is to this extent similar to works for performance, such as musical and theatrical pieces. However,

\footnotetext{
${ }^{26}$ It is possible for a curator-cum-artist to constitute a new work through appropriation and (perhaps non-standard) display of items created by others, as when Garry Neill Kennedy proposed that all landscape paintings in a particular wing of the National Gallery of Canada be re-hung at his eye level. However, such interventions do not change the original work; Kennedy's intervention did not make it the case that the original works he appropriated are now such that they must be hung at his eye level. For discussion of cases of incorrect installation, or conflict between the artist and the museum about appropriate display, see Irvin, 'Museums'.
} 
since the work is in the genre of contemporary visual art, where most works are singular rather than multiple, the permissibility of multiple instances becomes interpretatively relevant. Because the work can always be newly instanced after a particular instance goes out of existence, the eating of the last piece of candy loses much of the poignancy it would have had in case 2 (since, in case 4, it isn't really the last piece). The work becomes a meditation less on mortality and loss than, perhaps, on the way in which a person's spirit can live on and be reconstituted in different forms through the survival of those who knew and loved him. The work in case 4 seems fundamentally more optimistic than that in case 2 , and this interpretative fact is closely related to its ontological status as an abstract entity permitting multiple instances.

These examples illustrate two important points. First, as I described in the previous section, the artist's art-making role is not exhausted by the creation of a physical object. Gonzalez-Torres's art-making activity didn't involve making an object, or even specifying a particular object. Instead, he sanctioned the features of his work through acts related to presentation: by communicating instructions to the museum, giving the work a title, and so forth. Through these art-making activities, he made it the case that Untitled involves the presentation and periodic replenishment of a (roughly) 175-pound pile of candies that can be eaten by viewers. And by these same activities, he made it the case that the artwork is not identical to or essentially constituted by any presented pile. Through a different set of decisions, however, he could have made a work that was essentially constituted by a particular pile of candies, or a work that was an abstract entity, susceptible of multiple tokenings.

Second, there is a fit between the ontological status of the work and the interpretative properties that are appropriately attributed to it. When the artist chooses, whether implicitly or explicitly, to make a work that is essentially constituted by a particular physical object, this makes available certain kinds of interpretative content that could not have belonged to the work had the artist's sanction determined that it was, instead, a multiply instantiable type. Ontological status, like other elements of a work's form, is a resource artists can use to imbue their works with meaning. Acknowledging differences in the works' ontological status allows us to acknowledge important differences in the works' interpretative contents as well.

\section{Artworks, physical objects, and parameters}

I've suggested that because of the nature of the art-making process, the artwork can come unmoored from any particular physical object. Gonzalez-Torres's actual work cannot plausibly be thought to be identical to, to be essentially constituted by, or to have as a component any particular physical object, even one construed loosely, such as a pile. Moreover, the nature of the process by which artworks are created makes it the case that artists have it in their power to create different kinds of entity. Gonzalez-Torres could have made an artwork on the model of a sculpture, as in case 1, or an artwork on the model of a musical work, as in case 4. But he in fact made neither of these, opting for an artwork that, while not a multiple, can survive the destruction of any particular physical object or assemblage through which it is presented.

But can't we, nonetheless, find some interesting and informative things to say about the ontology of such works as a class? Isn't it still the case that the works are essentially tied to or constituted by or composed of physical objects in a way that would allow us to say something about what they all have in common, ontologically? It seems to me that going down the path of trying to find unifying claims to make about the ontology of such works is likely to mislead us, at best. We might be tempted to say, for example, that Kandinsky's Improvisation No. 7 is a painted canvas, whereas Felix Gonzalez-Torres's work is a pile of candy that is allowed to be eaten. But surely Kandinsky's work is an object in a quite different way than Gonzalez-Torres's work is. Gonzalez-Torres's work, if it is a pile of candy, isn't any particular pile of candy (even if we admit, as I think we should, that a pile of candy can survive a $100 \%$ replacement of its parts). For each time the work is put on display, a new pile of candy will be made. Moreover, as I mentioned earlier, the work 
continues to exist even when there is no pile of candy: even if the museum throws away all the old candies in between exhibitions, and has no objects in storage at all in relation to this work, the work itself has not been destroyed. The situation is quite different for Kandinsky's work: this work centrally involves a particular object and cannot go on existing if that object is destroyed.

Given widespread pre-theoretical intuitions, it seems attractive to maintain, whenever we can, that an artwork is a physical object. But even in the easiest sort of case, it will be at best misleading to say that the artwork is simply a physical object. Kandinsky's Improvisation No. 7, perhaps the most straightforward sort of case, is not simply a physical object; it is, at best, a physical object considered in a certain way, where the artwork cannot be grasped in the absence of such consideration. The object must be considered with the correct orientation, right-side-up rather than upside down or sideways. And, should some dirt begin to accumulate on its surface, or should a piece of paint flake off, it will not thereby become a dirty-work or a flaked-paint-work. Thus, if we wish to maintain that the work is a physical object, we must say that it is a physical object considered as though it were appropriately oriented and in pristine condition. The actual painted canvas that we see in the museum might not have all of these features; so gaining access to the artwork must involve going beyond what we see. Thus even a traditional painting is, at best, a physical-object-considered-in-a-certain-way; and the way in which it must be considered may well diverge from the way it actually is. A characterization offered by Amie Thomasson seems to fit such works: they are 'individual concreta (bearing physical properties perhaps among others) constituted by physical objects, but not identifiable with their constituting matter.'27

However, I have suggested that Gonzalez-Torres's work Untitled (Portrait of Ross in L.A.) is not a physical-object-considered-in-a-certain-way, since the work has a continuous existence, whereas no physical object that would be a candidate for an identity or constitution relation to the work exists continuously. To what ontological category, then, does the work belong? And if this ontological category is indeed viable, why can't ontological unity be preserved by assigning all artworks to this category?

The details of the case require that Gonzalez-Torres's work be construed as an individual concretum not essentially constituted by a physical object. ${ }^{28}$ The work can continue to exist in the absence of any particular physical object or assemblage; however, it is not an abstract entity on the model of a type or kind, since it is not susceptible of having multiple tokens or instances. The nature of the concretum is determined by a set of parameters for presentation expressed by the artist: the work is such that presentation of it involves the construction of a 175-pound pile of candy that audience members are allowed to consume, and that the museum is to replenish periodically.

It should be noted that even if it is possible to unite Untitled (Portrait of Ross in L.A.) with Kandinsky's Improvisation No. 7 under the label 'individual concreta', this does not

\footnotetext{
27 While regarding this as the most plausible construal of the view that artworks are closely associated with physical objects, Thomasson does not explicitly endorse this characterization. Amie Thomasson, 'The Ontology of Art', in Peter Kivy (ed.), The Blackwell Guide to Aesthetics (Malden, MA: Blackwell, 2004), p. 82.

${ }^{28}$ In drawing the distinction between abstract and concrete entities in a way that allows that an entity may be concrete without being partly constituted by a physical object, I am informed by Gideon Rosen's discussion of the Way of Abstraction in 'Abstract Objects', in Edward N. Zalta (ed.), The Stanford Encyclopedia of Philosophy (Spring 2006 edition), http://plato.stanford.edu/archives/spr2006/entries/abstract-objects/. A particular marriage or a particular bank account would also count as a non-physical concretum on this account (although, as in the case of an artwork that is a non-physical concretum, many physical events and states of affairs will be relevant to its having come into existence and acquired the properties it possesses). On some ways of drawing the abstract/concrete distinction, of course, such entities, though singular, will be termed abstract simply because they are not physically constituted.
} 
eliminate the ontological diversity of artworks. First, it is clear that ontologically diverse entities can be described as individual concreta: there is no reason to expect a common ontological account of the pebble caught in the tread of my boot, my present, occurrent thought about that pebble, and the sentence-token about the pebble that I am presently typing on my laptop. Second, as we saw earlier it is open to a visual artist to create a work that is an abstract rather than concrete entity: Gonzalez-Torres could have created a work that was susceptible of multiple instances, as in case 4, and said work would be abstract.

The recognition that some artworks are concreta partly constituted by physical objects, whereas others are non-physical concreta or abstract entities, is not aesthetically ineffectual. Creating different kinds of entities allows artists to imbue their works with different kinds of content. The ability to create a work that is a concrete non-physical entity allows Gonzalez-Torres to make a particular commentary on the nature of persons. Moreover, by creating a non-physical concretum that is presented through an assemblage of physical objects, Gonzalez-Torres bridges the domains of conceptual and traditional visual art, and this is an additional source of potential critical interest. To force works of this sort into the category of individual concreta identified with or essentially constituted by physical objects would rule out their possessing certain kinds of interpretative content that we appropriately attribute to them, and thereby violate the critical practice constraint.

Above, I stated that Gonzalez-Torres's creation of Untitled (Portrait of Ross in L.A.) involved the expression of a set of parameters for presentation. And, in general, my view about the artist's sanction suggests that such specification of parameters, whether explicit or implicit, is a crucial part of the process of creating an artwork. Even Kandinsky's creation of Improvisation No. 7 involved the expression of such parameters: correct presentation of his work requires that a particular painted canvas be hung flat on a wall with the painted side visible, and in a particular orientation. Why, then, can't we identify the work with the set of parameters that specify acceptable presentations, such that all artworks are construed as abstract entities and are susceptible of being brought together within a common ontological category? On such an approach, visual artworks could be treated jointly with musical works, which are often construed as abstract entities involving parameters for acceptable performances. ${ }^{29}$

The critical practice constraint mandates rejection of the view that visual artworks in general are to be identified with sets of parameters expressed by the artist, despite the attractiveness of such a view when applied to musical works for performance. It seems that we admire particular musical performances as aesthetic objects in their own right, and that a substantial portion of our admiration for the musical work itself is by virtue of the possibilities it creates for interesting performances. Our appreciative practices, then, provide some warrant for the idea that what is appreciated, when we appreciate a musical work, is a set of parameters: the parameters are what create the possibilities for aesthetically appealing performances. Moreover, a work for performance is less aesthetically replete than any performance of it, ${ }^{30}$ just as any set of parameters not stipulating a maximally determinate set of values will be less fully specified than an object satisfying those parameters. Our practices of appreciating musical works, then, make sense of the idea that a musical work is an abstract entity, perhaps aptly characterised as a set of parameters or norms for performance.

Critical practice does not, however, treat most visual artworks as sets of norms or parameters. A traditional painting is not of interest for the range of possible presentations

\footnotetext{
${ }^{29}$ For influential statements of such views, see Nicholas Wolterstorff, Works and Worlds of Art (Oxford: Clarendon Press, 1980), and Levinson, 'What a Musical Work Is'. Stephen Davies notes, in Musical Works and Performances: A Philosophical Exploration (Oxford: Oxford University Press, 2001), that some musical works, such as recordings of purely electronic music, are not for performance; such works may not be amenable to a construal as abstract entities.

${ }^{30}$ As S. Davies notes in Musical Works, ch. 1, this relation may vary from work to work, with some works being much 'thicker' than others.
} 
it creates. The parameters for its presentation are such as to make all permissible presentations fall within a very narrow range: the parameters will specify that a particular physical object be displayed in a particular orientation, so that viewers have a similar visual experience each time they encounter the object. Moreover, unlike many of the aesthetic properties of a performance of a musical work, the properties that are of aesthetic interest in a painting are not derived from a set of parameters specified by the artist; instead, most of the parameters (e.g., acceptable presentations of this work require the display of a particular painted canvas with such-and-such features) are generated implicitly through the application of paint to canvas. We do not look through the presentation of a painted canvas to infer the set of parameters the artist expressed, treating the parameters themselves as of substantial aesthetic interest; instead, we appeal to the parameters (such as those specifying correct orientation) so as to ensure that we are grasping the aesthetic features of the painted canvas appropriately. Moreover, it is not clear that a set of parameters, if it has any representational content at all, will have the same representational content as the object presented. The parameters expressed by the artist, then, are not of primary aesthetic interest in such traditional cases. To say that the artwork simply is the set of expressed parameters would be unjustifiably revisionist from the perspective of critical practice.

The fact that traditional works of visual art are not sets of parameters, however, does nothing to show that no contemporary artwork is a set of parameters. Similarly, my objections above to the view that artworks are in general to be assimilated to action-types or action-tokens do not rule out the possibility that some artworks are action-types or action-tokens; I take it that there are works of contemporary performance art falling into each of these categories. The problem with views that attempt to shoehorn all visual artworks into a single category is that they deny us the resources to acknowledge the very real and aesthetically relevant distinctions among works that function differently and bear quite different relations to their art historical predecessors. By creating works belonging to different ontological categories, artists may express distinct artistic content, and only a view that acknowledges the ontological diversity of artworks can capture this fact. ${ }^{31}$

\section{Grasping the artwork}

I have suggested that some artworks are abstract entities while others are individual concreta, some of which are partly constituted of particular physical objects while others, though not essentially constituted by physical objects, are presented by way of them. This raises the question, What is the relationship between what we see in a gallery on a given occasion and the artwork? The answer is that the artwork is never grasped exclusively through seeing: we never simply apprehend that a certain set of properties is interpretatively and evaluatively relevant by looking at some object, independently of rather detailed and specific background knowledge. For most artworks, many of their properties are grasped through vision. This is especially true for traditional paintings and sculptures. But invariably, even for traditional works, some properties must be grasped through cognition that is independent of vision. The correctness of a particular orientation of a painting cannot simply be grasped through vision; for it may be that the painting has been hung upside down, as with a large abstract painting I once saw in a Beijing museum. The relevance or irrelevance of the fact that paint is flaking off of the surface of a painting cannot simply be grasped through vision; one must know, independently of vision, either that the work falls under a convention making this fact irrelevant or that the artist has

\footnotetext{
31 Dominic McIver Lopes offers an argument for the ontological diversity of architecture, based on the fact that sound critical practice varies cross-culturally in such a way as to have ontological consequences. A similar argument might offer independent support for claims about the ontological diversity of visual artworks. See Lopes, 'Shikinen Sengu and the Ontology of Architecture in Japan', Journal of Aesthetics and Art Criticism 65 (2007), 77-84.
} 
suspended the convention and made the flaking paint part of the work. ${ }^{32}$ Because the background knowledge that establishes which features of the object are relevant varies from case to case, there is no straightforward algorithm for inferring the artwork based on the physical object. One must attend directly to the details of what the artist has sanctioned in the particular case.

It might seem unfortunate that we are forced to adopt a view that says artworks are not simply seen. But this fact may, in a sense, be a blessing: for it allows that even if the display is faulty, the audience's ability to grasp the work may be preserved. As any museum conservator knows, parts of contemporary artworks disappear on a regular basis. I know of one case in which over 20 percent of the pieces of an important contemporary artwork were stolen while the work was on loan from the museum that owns it. Indeed, I once saw a contemporary artwork that included many small plastic zip-top bags, each of which contained a small amount of material that had been stolen from someone else's work. It is clear, then, that many art objects are missing some of their physical components. And then there are all the ways in which curators can get instructions slightly wrong, or be forced to install a work in a space for which it wasn't initially envisioned. ${ }^{33}$ There's the fact that a painting may not be hung perfectly horizontally, so the correct orientation for display is not quite realized. Because grasping an artwork always involves grasping some properties that are not accessible through vision, and because it often involves ignoring outright some of the features of the object on display, these cases do not present insurmountable difficulties. We can consider the painting as if it were properly hung, and the contemporary installation artwork as if all its components were intact. If we do this, then we will have grasped the work the artist created - and this, I think, is the fundamental activity of the art audience: to grasp the work through both careful looking and careful thinking about what the artist has made. If we succeed in this, then we will be in a position to interpret and evaluate artworks much more successfully. ${ }^{34}$

\section{Bibliography}

Currie, Gregory, An Ontology of Art (New York: St. Martin's Press, 1989).

Danto, Arthur, The Transfiguration of the Commonplace: A Philosophy of Art (Cambridge, MA: Harvard University Press, 1981).

Davies, David, Art as Performance (Malden, MA: Blackwell, 2004).

Davies, David, 'Artwork, Action, and Process', Acta Analytica 20 (1988), 131-153.

Davies, Stephen, Musical Works and Performances: A Philosophical Exploration (Oxford: Oxford University Press, 2001).

Irvin, Sherri, 'The Artist's Sanction in Contemporary Art', Journal of Aesthetics and Art Criticism 63 (2005), 315-326.

Irvin, Sherri, 'Museums and the Shaping of Contemporary Artworks', Museum Management and Curatorship 21 (2006), 143-156.

Levinson, Jerrold, 'What a Musical Work Is', Journal of Philosophy 77 (1980), 5-28.

Lopes, Dominic McIver, 'Shikinen Sengu and the Ontology of Architecture in Japan', Journal of Aesthetics and Art Criticism 65 (2007), 77-84.

Rosen, Gideon, 'Abstract Objects', in Edward N. Zalta (ed.), The Stanford Encyclopedia of Philosophy (Spring 2006 edition), http://plato.stanford.edu/archives/spr2006/entries/abstract-objects/.

\footnotetext{
32 Of course, once one knows that the orientation of the painting is correct, or that the flaking paint is an element of the work, many of the work's properties, such as the colours and forms on the surface of the painting and the spatial relations among them, will be directly seen.

33 For discussion of such cases, see Irvin, 'Museums'.

34 I am grateful to Stephen Davies, Martin Montminy, and, especially, Kathleen Stock for comments on earlier versions of the manuscript.
} 
Sagoff, Mark, 'On Restoring and Reproducing Art', Journal of Philosophy 75 (1978), 453470.

Sautman, Anne, Self-Guide: Modern and Contemporary Art at the Art Institute (Chicago: Art Institute of Chicago, 2003).

Schimmel, Paul, 'Intentionality and Performance-Based Art', in Miguel Angel Corzo (ed.), Mortality Immortality? The Legacy of 20th-Century Art (Los Angeles: Getty Conservation Institute, 1999), pp. 135-140.

Stecker, Robert, 'The Ontology of Art Interpretation', in Stephen Davies and Ananta C. Sukla (eds.), Art and Essence (Westport, CT: Praeger, 2003), pp. 177-191.

Stock, Kathleen, review of David Davies' Art as Performance, Philosophical Quarterly 55 (2005), 694-696.

Thomasson, Amie, 'The Ontology of Art', in Peter Kivy (ed.), The Blackwell Guide to Aesthetics (Malden, MA: Blackwell, 2004), pp. 78-92.

Wollheim, Richard, Art and Its Objects, $2^{\text {nd }}$ edition (Cambridge: Cambridge University Press, 1980).

Wolterstorff, Nicholas, Works and Worlds of Art (Oxford: Clarendon Press, 1980). 